\title{
ULTRAPASSAGEM DE BARREIRA LINGUÍSTICA \\ E COOPTAÇÃO DE MÃO DE OBRA NO SUL DA BAHIA: PRIMEIROS ANOS DE COLONIZAÇÃO PORTUGUESA $(1500-1549)^{1}$
}

\author{
SUPERACIÓN DE LA BARRERA LINGÜÍSTICA Y COOPTACIÓN LABORAL EN EL SUR DE \\ BAHIA: PRIMEROS AÑOS DE COLONIZACIÓN PORTUGUESA (1500-1549)
}

OVERCOMING OF LINGUISTIC BARRIER AND COOPTATION OF LABOR IN THE SOUTH OF BAHIA: FIRST YEARS OF PORTUGUESE COLONIZATION (1500-1549)

Wagner Argolo Nobre* Universidade Estadual de Santa Cruz

RESUMO: Neste artigo, temos como principais objetivos a explicitação de como se deu a ultrapassagem de barreira linguística e a cooptação inicial de mão de obra para os engenhos de produção de açúcar, durante o início da colonização portuguesa no Brasil, com ênfase para a região sul da Bahia e para o período compreendido entre 1500 e 1549. Como objetivo secundário, procuramos ressaltar a importância do desenvolvimento, no âmbito da ciência linguística, da disciplina de história social da linguagem (BURKE, 1995), já que investiga um dos principais aspectos de uma língua: seu papel social, exercido por seus falantes em suas relações interpessoais cotidianas - dimensão digna de nota -, na medida em que o caráter bem sucedido das relações linguísticas iniciais, entre povos distintos, pode ser determinante para interações sociais menos deletérias, assim como produzir consequências importantes sobre a formação de uma identidade nacional.

PALAVRAS-CHAVE: História linguística. História social. Brasil colonial. Sul da Bahia.

RESUMEN: Este artículo tiene como objetivos principales hacer explícito cómo se superó la barrera lingüística y la cooptación inicial de mano de obra para los ingenios azucareros durante el comienzo de la colonización portuguesa en Brasil, con énfasis en la

\footnotetext{
${ }^{1}$ Artigo oriundo da Tese de Doutorado História linguística do Sul da Bahia (1534-1940), orientada pela Dra Tânia Lobo, da Universidade Federal da Bahia, e defendida em 2015, na mesma Universidade. Esta pesquisa contou com o apoio financeiro da CAPES-PDSE. A todos, deixo meu agradecimento.

* Doutor (2015), Mestre (2011) e Licenciado (2008) em Letras, pela Universidade Federal da Bahia. E-mail: wagner.argolo@gmail.com.
} 
región sur de Bahía y en el período comprendido entre 1500 y 1549. Como objetivo secundario, buscamos resaltar la importancia del desarrollo, en el ámbito de la ciencia lingüística, de la disciplina historia social del lenguaje (BURKE, 1995), ya que investiga uno de los principales aspectos de una lengua: su papel social, desempeñado por sus hablantes en sus relaciones interpersonales cotidianas - una dimensión notable-, ya que el carácter exitoso de las primeras relaciones lingüísticas entre diferentes pueblos puede ser determinante para interacciones sociales menos perjudiciales, así como tener consecuencias importantes para la formación de una identidad nacional.

PALABRAS CLAVE: Historia lingüística. Historia social. Brasil colonial. Sur de Bahia.

ABSTRACT: In this article, we have as main objectives the explanation of how it has been through the overcoming of the linguistic barrier and the initial cooptation of labor for the sugar mills ocurred during the beginning of the Portuguese colonization in Brazil, with emphasis on the southern region of Bahia and for the period between 1500 and 1549. As a secondary objective, we seek to emphasize the importance of the development, within the scope of linguistic science, of the discipline of social history of language (BURKE, 1995), since it investigates one of the main aspects of a language: its social role, exercised by its speakers in their daily interpersonal relations - a noteworthy dimension - to the extent that successful character of early linguistic relations between distinct peoples can be determinant for less deleterious social interactions, as well as having important consequences on the formation of a national identity.

KEYWORDS: Linguistic history. Social history. Colonial Brazil. South of Bahia.

\section{INTRODUÇÃO}

Quando o tema de trabalhos sobre a história linguística do Brasil é o percurso social que a língua portuguesa começou a traçar aqui, no início do Período Colonial, principalmente a partir de 1532, é comum encontrarmos cenários impressionísticos, como aquele que nos transmite a ideia de que a língua portuguesa, logo que aportou na costa sul baiana, em 1500, na boca de quatro grumetes da frota de Pedro Álvares Cabral, imediatamente espalhou-se como rastilho de pólvora entre os autóctones, por ser a língua de um povo num estágio evolutivo mais avançado, em detrimento da língua predominante da costa, o tupinambá.

Entretanto, como veremos neste artigo, o cenário linguístico do século XVI foi bastante diverso. Indo além, podemos afirmar, com segurança, que a fácil ultrapassagem da barreira linguística, por parte dos portugueses recém-chegados, deu-se, justamente, pelo fato de terem adotado o tupinambá como língua de comunicação supra-étnica, tornando-se bilíngues em português, como primeira língua, e tupinambá, como segunda língua.

É neste contexto linguístico que tem início a colonização do Brasil, feita de forma pontual, num primeiro momento, a partir de 1500 , através das expedições guarda-costa, e de forma intensa, num segundo momento, a partir de 1532, com a chegada de Martim Afonso de Souza a São Vicente, no atual estado de São Paulo, quando começa o processo que culminará na fundação das Capitanias Hereditárias, dois anos depois, em 1534. A ultrapassagem da barreira linguística, levada a termo com a adoção da língua tupinambá pelos portugueses, foi, justamente, o principal fator que possibilitou as negociações com os índios da costa, nos primeiros 34 anos, no intuito de se obter mão de obra indígena escravizada para os trabalhos iniciais nos engenhos de produção de açúcar. De início, com a conivência dos próprios tupinambás, que disponibilizavam alguns de seus prisioneiros indígenas, capturados nas guerras inter-tribais, para negociá-los como escravos com os portugueses, mantendo, porém, o controle sobre a oferta desses prisioneiros, preservando-se a bilateralidade das relações.

A partir da fundação das Capitanias Hereditárias, entretanto, a aliança militar bilateral transformar-se-ia num processo de dominação unilateral, que teria como resultado a escravização em massa dos tupinambás, sem qualquer reconhecimento de sua autoridade tribal secular, principalmente a partir do momento em que os engenhos de produção de açúcar, que demandavam um grande contingente de mão de obra, são fundados no intuito de incrementar e sedimentar o processo de colonização do Brasil, necessidade que se acentua depois que o comércio de especiarias com a Índia começa a apresentar seus primeiros sinais de desaquecimento. 
Lidando com esses dois importantes temas - a maneira como se ultrapassou a barreira linguística inicial e o início da imposição de um domínio colonial, incluindo a escravização dos povos dominados como forma de cooptação de mão de obra -, este artigo procura lançar luzes sobre aspectos pertinentes tanto para linguistas quanto para historiadores, contribuindo, assim, para o desenvolvimento de uma nova disciplina que emerge, nos últimos anos, no locus situado entre a ciência linguística e a ciência histórica, ou seja, a história social da linguagem, como bem salientou o historiador inglês, Burke (1995, p. 26), afirmando ainda ser, este, "um campo promissor para a cooperação interdisciplinar".

Bessa Freire (2004, p. 21) - entre historiadores, um dos pioneiros deste campo no Brasil - já afirmava que "[...] esse novo campo ainda não foi suficientemente explorado [...]", em seguida asseverando que "A historiografia brasileira tem se dedicado, com sucesso, aos aspectos administrativos, políticos e econômicos sem incorporar, no entanto, a trajetória histórica das línguas ou a evolução de suas funções como objeto de preocupação e de análise”.

Além disso, o autor deixa bastante clara a importância do desenvolvimento da disciplina de história social da linguagem, ao destacar seu descontentamento por observar a pouca relevância que vem sendo dada ao tema, "[...] embora sem ele não seja possível compreender o processo de interação conflituosa entre índios e colonizadores, ou revelar determinados componentes das matrizes formadoras da nacionalidade" (BESSA FREIRE, 2004, p. 21).

Entretanto, quando observamos essa relação interdisciplinar do ponto de vista dos linguistas, tanto brasileiros quanto portugueses, que trabalham com a história do português brasileiro e do português europeu, a relevância de aspectos típicos da ciência histórica como os administrativos, políticos e econômicos - já vem tendo seu peso devidamente reconhecido há décadas, como se pode constatar, por exemplo, na História da língua portuguesa, escrita pelo brasileiro Serafim da Silva Neto no início da década de 1950 e já tão conhecida e citada pelos linguistas portugueses que também lidam com a história de sua língua-mãe. É o que podemos perceber claramente em trechos da referida obra, a exemplo deste em que expõe as seguintes reflexões: "Se a língua é um fenômeno social que só existe entre os homens e para eles, é imperativo e justo que se faça a história do instrumento através daqueles que o dominam" (1957, p. 10). Daí afirmar, sobre seu livro, que "[...] nele a história entra como o painel que dá realidade aos fatos. Afinal, e em última análise, a história de uma língua consiste numa história dos contactos a que estão sujeitos os que a falam: e isso nos leva à história política e administrativa" (SILVA NETO, 1957, p. 10).

\section{O INÍCIO DA COLONIZAÇÃO E AS PRIMEIRAS INTERAÇÕES LINGUÍSTICAS}

Nos séculos que precederam a chegada dos portugueses à costa atlântica sul-americana, os tupinambás/tupis/tupiniquins (essas são as denominações mais recorrentes para os povos falantes da língua então majoritária na costa do Brasil) partiram para a dominação territorial de toda a faixa costeira, escrevendo mais um capítulo das constantes guerras autóctones pré-coloniais, com o objetivo de dominar as regiões com as melhores condições ecológicas para a manutenção da vida.

Quando os portugueses iniciaram a colonização efetiva do Brasil, já em 1532, mas principalmente a partir de 1534, quando são oficialmente fundadas as capitanias hereditárias, os tupinambás/tupis/tupiniquins ainda estavam terminando de expulsar para o sertão as últimas etnias inimigas, nomeadamente as que falavam línguas do tronco Macro-Jê (COUTO, 1998). Tal processo de dominação, entretanto, já estava consolidado: "Nos últimos séculos [...], índios de fala tupi, bons guerreiros, se instalaram, dominadores, na imensidade da área [...], ao longo de toda a costa atlântica [...]” (RIBEIRO, 2004 [1995], p. 29).

O domínio dos tupinambás/tupis/tupiniquins ${ }^{2}$, entretanto, quando ainda estava recentemente consolidado no âmbito da realidade autóctone da América do Sul, foi interrompido por um elemento externo e completamente estranho ao que conheciam: o pequeno contingente português que chegava com a intenção de implantar uma colônia de exploração agrícola, com vistas a inserir sua

\footnotetext{
${ }^{2}$ Ribeiro (2004 [1995]) afirma que os índios que dominaram a costa atlântica do Brasil falavam uma mesma língua. Métraux (1948) faz afirmação semelhante e acrescenta que, no que se refere à etnia desses autóctones, o termo "tupinambá" era o mais recorrente, por isso aplicando-o para designar todos os índios da costa. Dentro da mesma lógica, estenderemos a generalização da denominação também à língua, chamando-a, igualmente, daqui para a frente, de "tupinambá”, seguindo Rodrigues (1986).
} 
produção no mercado internacional europeu, e a transformá-la numa grande fonte de mão de obra escrava indígena e de pedras e metais preciosos: "Embora minúsculo, o grupelho recém-chegado de além-mar era superagressivo e capaz de atuar destrutivamente de múltiplas formas", ao mesmo tempo em que articulava "[...] os novos mundos ao velho mundo europeu como provedores de gêneros exóticos, cativos e ouros” (RIBEIRO, 2004 [1995], p. 30).

Por causa da dominação costeira dos tupinambás, quando os portugueses iniciaram a colonização do litoral brasileiro, havia cerca de um milhão destes índios habitando a região (população numericamente semelhante à de Portugal inteiro no período), distribuídos em tribos com cerca de 300 a 2 mil pessoas, falando uma língua comum, também conhecida como tupinambá (RIBEIRO, 2004 [1995]).

Não podemos deixar de ressaltar, entretanto, que qualquer estimativa demográfica sobre o Brasil, em seus primeiros 250 anos, será sempre um "terreno movediço", pois os dados empíricos para esse fim, quando existem, são esparsos, incompletos e indiretos, permitindo apenas inferências a esse respeito. Isto porque, até 1760, não foram levadas a termo contagens - quer gerais, quer regionais - da população brasileira; e, no que se refere a recenseamentos eclesiásticos, há uma grande incerteza quanto a refletirem o total das populações recenseadas (cf. MATOS, 2013). Esses são os motivos que levaram Marcílio, em A população do Brasil colonial (2004), a ser enfática no que se refere a estimativas demográficas situadas nos dois primeiros séculos da colonização do Brasil, afirmando ser este período conhecido, na demografia histórica, como fase pré-estatística. ${ }^{3}$ Desse modo, informa-nos que, sem dados, “[...] não há demografia, e no caso do Brasil não há praticamente nenhuma informação estatística referente aos primeiros 250 anos de sua existência. Toda informação útil existente para o estudo da população é incompleta, indireta e somente em casos excepcionais serializada". Por causa disso, "[...] não se pode fazer qualquer análise demográfica realmente elaborada com base nesse tipo de informação". Daí afirmar que esta "[...] é a chamada fase pré-estatística dos estudos sobre a população brasileira. Durante esse período, não foi feita nenhuma contagem por cabeça, nem numa base geral ou regional nem mesmo setorial”. E encerra a questão, afirmando que "[...] não se pode dizer se os registros das igrejas (batismos, casamentos e atestados de óbito), mesmo quando mantidos com regularidade, deram conta de toda a população. O pior, porém, é que mesmo estes raramente chegaram intatos à posteridade" (MARCÍLIO, 2004, p. 311).

Assim, é tendo em mente o que lemos nos trechos extraídos de Marcílio (2004) que devemos encarar os dados demográficos estimados por Hemming (1987) para os territórios que viriam a compreender as Capitanias de Ilhéus e do Espírito Santo, consideradas em conjunto, quando os portugueses chegam ao Brasil em 1500. Segundo o autor, esses dois territórios somariam uma população de 160 mil autóctones - nesse caso, considerando-se a região costeira das capitanias, principalmente tupinambás. Com relação à Capitania de Porto Seguro, nenhum dado é apresentado.

Como dissemos, Hemming apresenta a estimativa demográfica da Capitania de Ilhéus em conjunto com a estimativa demográfica da Capitania do Espírito Santo. Por essa razão, só podemos chegar a um número para a Capitania de Ilhéus, isoladamente, se considerando que as referidas capitanias tinham aproximadamente a mesma extensão costeira (como visualmente se constata em mapas das capitanias hereditárias) - dividirmos os 160 mil índios, nomeadamente da costa das Capitanias de Ilhéus e do Espírito Santo, por dois, para obter a média de 80 mil autóctones por capitania.

Outra estimativa para o século XVI que, dentro desse "terreno movediço", podemos fazer - nesse caso, tanto para os tupinambás da Capitania de Ilhéus quanto para os tupinambás da Capitania de Porto Seguro - tem sua base em Anchieta (1584), na sua Breve informação do Brasil, e em Ribeiro (2004 [1995]), no seu clássico O povo brasileiro. Isto porque, ao referir-se ao fato de uma só língua ser a utilizada em quase 800 léguas de costa, desde o Maranhão até São Paulo, Anchieta permite que façamos o cálculo, extremamente simples, de dividir os um milhão de tupinambás da costa - falantes dessa "uma só língua” -, estimados por Ribeiro, pelo número de capitanias hereditárias - 15 ao todo -, delimitadas no primeiro momento da colonização, iniciada efetivamente na década de 1530, como já foi dito. Vejamos o que diz o jesuíta:

\footnotetext{
${ }^{3}$ A partir de 1760, devido às Reformas Pombalinas, elaboram-se recenseamentos com alguma sistematização nas cidades, vilas e municipalidades do Brasil. Porém, em muitos casos, ou não foram feitos ou, se o foram, não exprimiram a realidade local. Mesmo assim, os dados começam a existir, razão pela qual essa data inicia a fase proto-estatística. Em 1872, é realizado o primeiro recenseamento geral, iniciando a fase estatística no Brasil (Marcílio 2004).
} 
Desde o rio do Maranhão, que está além de Pernambuco para o norte, até a terra dos carijós, que se estende para o sul, desde a Lagoa dos Patos até perto do rio que chamam de Martim Afonso, em que pode haver 800 léguas de costa [...], há uma só língua. (ANCHIETA, 1584 apud ALTMAN, 2003, p. 60)

Feita a conta (1.000.000/15), temos, como resultado, a média de 66.666 tupinambás por capitania, que, no caso das Capitanias de Ilhéus e de Porto Seguro, cremos poder ser arredondados para 80 mil, visto que as referidas capitanias eram das maiores da colônia, atingindo, assim, números próximos, no que se refere à Capitania de Ilhéus, aos que extraímos dos dados de Hemming (1987), relativos à mesma capitania - reforçando, por conseguinte, o raciocínio exposto. Desse modo, o diminuto contingente português que chegou ao Sul da Bahia ter-se-ia visto imerso num contingente de cerca de 160 mil tupinambás - mais do que 10\% da população de Portugal.

Se tivermos em mente as palavras de Anchieta, escritas logo na capa de sua Arte de Gramática, quando afirma que descreve a "língua mais usada na costa do Brasil” (ANCHIETA, 1595) - ou seja, usada pelos tais um milhão de tupinambás -, é possível compreender a razão de os portugueses, no momento em que deram início à colonização do Brasil, terem considerado mais viável adquirir a língua tupinambá do que tentar impor a língua portuguesa a esses índios.

O contingente tupinambá era numericamente muito superior ao de portugueses, fato que, apesar de não impedir a imposição de uma língua, torna, entretanto, sua imposição, através de meios militares e mesmo catequéticos, muito mais dificultosa, principalmente no caso em questão, em que eram os portugueses os que estavam em território estranho, o que se constituía em fator de vulnerabilidade, ao menos nas primeiras décadas, enquanto o território ainda não se tornava conhecido. Além disso, o imenso contingente tupinambá, além de ser numericamente superior e de estar em seu território, já possuía uma língua comum, não havendo qualquer necessidade de adquirir um novo código de intercomunicação. Muito pelo contrário, tal necessidade afigurouse para os portugueses.

Além disso, no século XVI, o português era uma língua ainda utilizada quase apenas na Europa, consequentemente passível de categorizar aspectos socioculturais e naturais europeus, e não desta região do Novo Mundo ainda por ser devassada.

Por fim, os jesuítas, que chegaram em 1549 - juntamente com Tomé de Sousa, vindo para implantar o primeiro Governo-Geral do Brasil -, adotaram como política linguística o aprendizado da língua dos povos que buscariam catequizar, e não o contrário. Tal política tinha como finalidade facilitar a interação com os povos recém-contactados, com vistas a obter melhores resultados, em termos de catequese, desses povos. É o que deixa claro o trecho de Tratados da terra e gente do Brasil, escrito pelo jesuíta Cardim em 1583, o que atesta o enraizamento dessa situação linguística na costa brasileira, ao longo das primeiras décadas do século XVI:

Em toda esta província [referindo-se ao Brasil como um todo] há muitas nações de diferentes línguas, porém uma é principal que compreende algumas dez nações de índios: estes vivem na costa do mar, e em uma grande corda do sertão, porém são todos estes de uma só língua ainda que em algumas palavras discrepam e esta é a que entendem os portugueses; é fácil, e elegante, e suave, e copiosa, a dificuldade dela está em ter muitas composições; porém dos portugueses, quase todos os que vêm do Reino e estão cá de assento e comunicação com os índios a sabem em breve tempo, e os filhos dos portugueses, assim homens como mulheres, principalmente na Capitania de São Vicente [onde efetivamente começou a colonização do Brasil, como dissemos], e com estas dez nações de índios têm os Padres comunicações por lhes saberem a língua, e serem mais domésticos e bem inclinados. (CARDIM, 2009 [1583], p. 200)

\section{A FUNDAÇÃO DAS CAPITANIAS DE ILHÉUS E DE PORTO SEGURO}

Até a fundação das Capitanias de Ilhéus e de Porto Seguro, as relações entre portugueses e tupinambás, que já existiam desde 1500 , através das expedições guarda-costa, tinham sido harmônicas, devido à instituição social tupinambá denominada cunhadismo ou cunhadaço, através da qual portugueses amasiados com índias dessa etnia tinham garantidos os favores de seus cunhados - assim como de praticamente toda a parentela da mulher -, que incluíam obrigações guerreiras, políticas e sociais. Desse modo, alianças entre portugueses e tupinambás foram estabelecidas nesse primeiro momento. 
Essas alianças eram aproveitadas pelos portugueses como uma forma de conseguir mão de obra indígena gratuita. Isto porque os tupinambás, além de viverem em estado de guerra constante entre si, também estavam em guerra constante contra os índios tapuias, expulsos para o sertão.

Dessa maneira, através dos tupinambás aliados, os portugueses obtinham os chamados "índios de corda”, ou seja, índios de tribos inimigas que eram capturados, com o intuito de serem devorados em rituais antropofágicos, mas que, em vez disso, eram entregues aos portugueses para serem escravizados. A historiadora Paraíso (1993, p. 183) informa-nos que "Os conflitos entre os grupos Tupi eram comuns e igualmente o eram entre estes e os Macro-Jê" e que "Estas oposições e estado de guerra constante foram usados pelos colonos no estabelecimento de alianças, obtenção de mão de obra, através da aplicação da regra Tupi de Cunhadaço, e na obtenção de “Índios de corda”".

Os tupinambás, por sua vez, consideravam os portugueses importantes aliados nas guerras contra seus inimigos, tanto os de mesma língua, quanto os de línguas do tronco Macro-Jê: “Também os íncolas viam nos colonos a possibilidade de obterem aliados poderosos contra os seus inimigos tradicionais [...]" (PARAÍSO, 1993, p. 183). Percebemos, portanto, que Paraíso (1993), neste artigo intitulado De como se obter mão de obra indígena na Bahia entre os séculos XVI e XVIII, e Ribeiro (2004 [1995]), em seu livro O povo brasileiro, concordam no que se refere ao cunhadismo ou cunhadaço como prática cultural tupinambá que facilitou a formação das alianças iniciais com os portugueses, fato que aponta para a pertinência dessas afirmações.

Ainda nesse período das alianças iniciais, anterior à fundação da Capitania de Ilhéus, já havia casos em que navios portugueses enviavam índios cativos para Portugal. Porém, por não ser uma prática sistemática e pelo fato de os tupinambás acreditarem que existia uma “terra sem males”, além das águas, perto do sol nascente, chamada Maíra, essas escravizações pontuais não deviam gerar conflitos, pois os cativos - ignorando que esta era sua nova condição - acreditavam estar indo para o lugar sonhado, e não para onde estava sua perdição. Como não havia maneira de os que ficaram saberem do resultado final da viagem, ficava a crença de que, para aqueles que tinham ido, uma graça tinha sido alcançada (PARAÍSO, 1993).

O Brasil passou a ser visto pelos portugueses como uma chance de angariar mais poder diante dos demais reinos europeus, devido às riquezas naturais que havia aqui, mas que não havia em Portugal. Somando-se isto à ideia de formar no novo território uma nova nobreza, de enriquecer facilmente sem grandes investimentos e à visão negativa que se tinha sobre os trabalhos manuais, temos algumas motivações que podem explicar a pretensão, que viria a concretizar-se, de escravizar os índios encontrados na costa sul da Bahia, para serem utilizados como mão de obra nas primeiras plantações de cana e nos primeiros engenhos de produção de açúcar a serem erigidos brevemente: "Carentes de grandes capitais para investir, os colonos viam no trabalho indígena a grande solução, principalmente por sua abundância e a exigência de baixos investimentos para sua obtenção” (PARAÍSO, 1993, p. 181).

Com a fundação das Capitanias de Ilhéus e de Porto Seguro, a escravidão indígena tornou-se um processo legal e de caráter sistemático - registrada, inclusive, em regimentos de sesmarias -, tanto no que se refere a sua utilização como mão de obra local quanto no que se refere a seu envio para a escravização em Portugal, estabelecendo-se, inclusive, um limite pré-definido de cativos que poderiam ser enviados para Lisboa e isenções fiscais a quem não desrespeitasse tal limite, embora não se tenha notícias da maneira como acontecia a escravização dos índios na metrópole lusa. Com maiores detalhes, Paraíso (1993, p. 185) informa que esse processo "[... já estava agora legalmente instituído, como se pode observar, por exemplo, no Regimento da Sesmaria concedida a Pero de Góes [...]”, dentro do qual constava a permissão para “[...] enviar 'dezessete peças de escravos' por ano nos navios que mandasse a Portugal, além de poder 'cativar gentios para seu serviço e dos navios' e vendê-los em Lisboa”, além da informação de que "Caso não ultrapassasse a cota anual, estaria, inclusive, liberado do pagamento da siza".

Quanto a limites de cativos para o trabalho nas primeiras plantações de cana do Sul da Bahia, não nos parece ter havido um préestabelecido, a não ser o da capacidade guerreira individual de cada donatário e sesmeiro para subjugar e cativar.

Nem todas as obras que utilizamos, na escrita deste artigo, apresentam informações setorizadas, estabelecendo uma fronteira entre processos que tiveram lugar na Capitania de Ilhéus e processos que tiveram lugar na Capitania de Porto Seguro. Isto porque tal 
fronteira é resultado de uma divisão exógena, vinda da Europa, e de caráter meramente político e econômico, sem qualquer consideração de cunho cultural sobre o que se dividia. Dessa maneira, há processos envolvendo índios (a exemplo do processo de cooptação de mão de obra), principalmente tupinambás, que aconteceram nas duas capitanias, mas que, na prática, davam-se da mesma forma, como se fossem um único território.

No momento em que, para os índios tupinambás, o Sul da Bahia era um único território, pois, como foi dito, a divisão em capitanias era de origem europeia, a busca por sua mão de obra poderia ocorrer em qualquer um dos lados do rio Jequitinhonha (fronteira delimitada pelos portugueses entre a Capitania de Ilhéus e a de Porto Seguro), tendo os portugueses de ir buscá-los nos pontos da costa em que estivessem, fosse ele qual fosse. Assim, a divisão inicial entre as duas capitanias, provavelmente, não foi de grande relevância no que se refere à imposição de limites territoriais onde pudesse ser feita a obtenção de mão de obra - até porque era difícil controlar as fronteiras de um território de mais de quinhentos quilômetros de costa -, sendo mais adequado falar em "Sul da Bahia”, no que se refere à cooptação de mão de obra na primeira metade do século XVI.

Possivelmente, é esta a razão pela qual Paraíso (1993), ao tratar da forma como se obtinha a mão de obra indígena nas capitanias em questão, o faz sem uma divisão exata entre as duas, tratando o Sul da Bahia, em grande parte do texto, como um todo único. Enfim, se as capitanias eram distintas, os índios eram os mesmos, demandando o mesmo tipo de ação por parte dos portugueses.

Vilhena, cronista baiano do século XVIII, também permite raciocínio semelhante, ao tratar com seu interlocutor, Filopono - que não se sabe se era real ou fictício -, no início da Carta Décima-Quinta, das notícias que começaria a dar sobre a Capitania de Porto Seguro, fazendo referências à Capitania de Ilhéus (descrita na Carta Décima-Quarta, imediatamente anterior):

Logo que te fiz aquela remessa cuidei em prontificar, e ordenar as notícias mais exatas da comarca de Porto Seguro [no final do século XVIII, as capitanias do Sul da Bahia já tiveram seu status administrativo modificado para o de comarcas] confinante com aquela de Ilhéus, seguindo de Norte a Sul, cujas notícias são pelos mesmos motivos igualmente interessantes. (VILHENA, 1969 [1798-1799], p. 517, grifo nosso)

\section{O DESVELAR DA DOMINAÇÃO E A “ESCRAVIDÃO NA PRÓPRIA TERRA”}

Com a fundação das Capitanias de Ilhéus e de Porto Seguro, chega o momento em que se desfazem as ilusões e se iniciam os conflitos entre portugueses e tupinambás, pois, com a sistematização do cativeiro, os índios perceberam que os portugueses, na realidade, não buscavam relações simétricas de aliança, mas a dominação do território: "Agora já não se tratava de ilusão da viagem para a Terra sem Males, além do grande rio. Era o aldeamento e sedentarização forçados e a escravidão na própria terra” (PARAÍSO, 1993, p. 186).

Ademais, com o incremento da atividade açucareira, ocorrido no momento inicial, houve o crescimento da demanda por mão de obra, fazendo com que os portugueses exigissem, cada vez mais, a entrega dos "índios de corda", ou seja, daqueles que seriam devorados nos rituais de antropofagia. Este fato, além de gerar reações negativas por parte dos que tinham capturado os índios destinados ao banquete, gerava reações negativas por parte dos próprios índios que seriam banqueteados. Não podemos nos esquecer das palavras de Fausto, em Fragmentos de história e cultura tupinambá, quando diz que, para os guerreiros desta etnia, "O estômago do inimigo era a sepultura ideal" (FAUSTO, 1992, p. 392).

Desse modo, ao livrar os tupinambás do ritual antropofágico e escravizá-los, os portugueses os submetiam a duas humilhações: a de ser escravo e a de não poder mais usufruir da morte honrosa. Os seguintes trechos de Paraíso (1993, p. 186) também são bastante contundentes a esse respeito, ao afirmar que "[...] a crescente consciência da unilateralidade dos direitos, só garantidos aos portugueses, e dos deveres cobrados aos índios começa a despertar sua consciência de que a suposta aliança [...] não se constituía numa unidade ordenadora das relações". Assim, "O desrespeito à lógica interna de sua sociedade levava-os a questionar os benefícios da suposta aliança, principalmente quando a emergente necessidade de mão de obra passou a exigir que os cativos, destinados aos rituais antropofágicos, fossem entregues aos portugueses”, provocando reações “[...] tanto dos captores quanto dos capturados”. 
Outro fator que veio a agravar os conflitos foi a incompatibilidade entre o modo de divisão do trabalho tupinambá e o modo de divisão do trabalho português. Isto porque, para os tupinambás, as atividades de plantação eram incumbência das mulheres, cabendo aos homens a derrubada das matas e as queimadas. Entretanto, era justamente para a atividade de plantação que os portugueses mais desejavam a mão de obra masculina tupinambá. Como se negavam a exercer tais atividades, mais atritos ocorriam, pois o colonizador não conseguia compreender a recusa à realização das atividades de plantação, vendo nisso uma manifestação da preguiça, e não um choque entre as concepções tupinambá e portuguesa de como se deveria dividir o trabalho entre homens e mulheres. Assim, Paraíso (1993, p. 188) afirma que, "Enquanto os colonos desejavam o concurso da mão de obra masculina para as atividades agrícolas, os homens aceitavam realizar, apenas, as tarefas de derrubadas e queima". E continua, afirmando que "As demais atividades, por serem atribuídas às mulheres, eram rejeitadas, o que não era compreensível ou aceitável pelos colonos”.

Como questão também fulcral, a minar as relações entre tupinambás e portugueses, estava o fato de a produção tupinambá ter finalidade comunitária e de contribuir para a formação de alianças, e não para o acúmulo de bens. E, para somar-se a este choque, ainda havia o fato de que, para atingir-se o nível de produtividade exigido pelos portugueses, os índios tinham de utilizar o máximo de seu tempo executando as tarefas impostas pelos colonos, não sobrando o tempo de que precisavam para estabelecer as relações inter-tribais tradicionais - o que incluía as alianças guerreiras e as próprias guerras em si, para vingar ancestrais, além dos rituais de antropofagia daí decorrentes, e que tanta satisfação e honra traziam para vencedores e vencidos.

Como uma tentativa de romper estes obstáculos culturais de forma menos drástica, partiu-se para a formação de aldeamentos coloniais, ainda antes da chegada dos jesuítas, nas áreas das próprias tribos originais, aos quais diversos índios eram integrados forçosamente. Essa forma de cooptação de mão de obra, entretanto, modificou-se à medida que os colonos começaram a transferir índios das áreas originais de suas tribos, para áreas que fossem mais convenientes para suas atividades de produção mercantil. Tais medidas, além de tornarem mais cômodo o acesso à mão de obra dos índios, deixavam-nos mais vulneráveis à imposição do sistema de produção econômico português (PARAÍSO, 1993, p. 187).

Pouco depois, chegariam, com Tomé de Sousa, os jesuítas, que viriam a assumir o controle dos aldeamentos, passando a exercer, como aliás veio a acontecer nas demais regiões da colônia onde atuaram, o papel de cooptadores de índios para servir de mão de obra, que, concentrados nos aldeamentos jesuíticos, eram separados e distribuídos para trabalhar como escravos para os colonos e para a Coroa, embora a justificativa para a dominação fosse a expansão da fé dos católicos.

\section{O SUL DA BAHIA E SUA CONFIGURAÇ̃̃O SOCIOLINGUÍSTICA NO SÉCULO XVI}

Diferentemente do que pode ter ocorrido com os escravizados africanos no ambiente das plantações de cana de açúcar, principalmente do Recôncavo Baiano (para nos restringirmos apenas ao atual estado da Bahia), as plantações de cana de açúcar do início da colonização das Capitanias de Ilhéus e de Porto Seguro certamente não se constituíram em espaços favoráveis à formação de pidgins e crioulos. ${ }^{4}$ Estes termos, por sua vez, referem-se a línguas derivadas daquelas dos povos dominadores, que se formam em ambientes de extrema violência, como os da escravidão, inicialmente como segunda língua da população adulta subjugada (estágio de pidgin), tornando-se a primeira língua da geração seguinte (estágio de crioulo), composta pelos filhos desses adultos. No estágio inicial de pidgin, apresentam muitas lacunas estruturais, devidas ao processo de transmissão linguística irregular que as gerou. No estágio mais avançado de crioulo, depois de nativizadas pela nova geração, têm essas lacunas completamente preenchidas por mecanismos gramaticais novos, oriundos da Gramática Universal, presente no cérebro humano, acessada no momento de aquisição da linguagem por crianças em seus primeiros anos de vida (BAXTER; LUCCHESI, 2009; LUCCHESI, 2012; HOLM, 2000).

Desse modo, tal diferença de contextos linguísticos ocorreu, porque este tipo de língua, inicialmente precária, surge como uma maneira de ultrapassar a barreira da falta de comunicação, já que o contingente que o utiliza é composto por falantes de diversas

${ }^{4} \mathrm{O}$ caso da antiga colônia Leopoldina, atual Helvécia, distrito da cidade de Nova Viçosa, no Sul da Bahia - onde houve a pidginização e a posterior crioulização do português, em contato com línguas africanas -, só veio a configurar-se três séculos depois, a partir de sua fundação em 1818. Mesmo assim, situa-se no hinterland, e foi parte de um contexto sociolinguístico muito específico em relação ao restante da região (para maiores informações a esse respeito, cf. Lucchesi, 2012). 
línguas ininteligíveis entre si, restando, como única língua disponível a todos, a do dominador. Esta, por sua vez, torna-se a línguaalvo, que os dominados são obrigados a adquirir sem qualquer sistematização e com acesso limitado a suas estruturas, donde a transmissão linguística irregular que a transforma numa língua distinta tanto daquela do dominador quanto daquelas dos dominados, mantendo, porém, grande parte do léxico da língua do dominador, da qual derivou, sendo, por isso, chamada de língua lexificadora (BAXTER; LUCCHESI, 2009; LUCCHESI, 2012; HOLM, 2000).

No caso das plantações de cana de açúcar do Sul da Bahia, tal barreira linguística já havia sido ultrapassada, pois a quase totalidade dos índios escravizados sabia falar a mesma língua supra-étnica autóctone, o tupinambá, por serem nativos da região, na qual já haviam estabelecido suas relações sociais há séculos. Em tal situação, quem se viu na contingência de ter de adquirir um novo código de comunicação, para poder estabelecer as primeiras relações sociais, foram, justamente, os colonizadores portugueses, tendo o tupinambá se tornado a língua-alvo. Ademais, o acesso a suas estruturas linguísticas era extremamente abundante, pelo fato de seus falantes constituírem o maior contingente demográfico, permitindo que os portugueses, mesmo sem um processo sistemático de aprendizado, adquirissem o tupinambá de forma plena, não abrindo caminho para processos de pidginização e de crioulização, mas, sim, para o bilinguismo português-primeira língua/tupinambá-segunda língua, por parte dos colonos lusitanos recém-chegados. Desse modo, até por uma questão prática, era mais vantajoso, para os portugueses, adquirir o tupinambá como segunda língua, principalmente se considerarmos que, ao o adquirir, estariam aptos para interagir linguisticamente ao longo de quase toda a vasta e rica costa brasileira.

Essa situação demográfico-social propícia ao bilinguismo prolongar-se-ia, nas Capitanias de Ilhéus e de Porto Seguro, durante quase todo o Período Colonial, começando a alterar-se em favor da língua portuguesa, apenas, a partir de 1760, devido - em menor grau - às Reformas Pombalinas e - em maior grau - ao início da prosperidade da lavoura cacaueira na região.

\section{CONCLUSÃO}

Neste artigo, abordamos, na Introdução, o fato de ter sido o tupinambá a língua que possibilitou a interação social entre portugueses e índios dessa etnia, principalmente, nos primeiros 50 anos de colonização da costa brasileira, no século XVI, constituindo-se, isto, no principal argumento para apontarmos o caráter impressionístico de trabalhos linguístico-históricos que desconsideram tal cenário, transmitindo a ideia distorcida de que a língua portuguesa teria começado a alastrar-se sobre este território no exato momento em que os primeiros grumetes portugueses pisaram no solo sul-baiano em 1500. Em seguida, ressaltamos o quanto a elucidação dessa questão, assim como a do mecanismo de cooptação de mão de obra indígena para o trabalho escravizado, pode lançar luzes sobre o desenvolvimento da disciplina de história social da linguagem, como proposta por Burke (1995).

Logo após, na seção O início da colonização e as primeiras interações linguísticas, procuramos explicar - através de projeções demográficas e do depoimento de gramáticos e de cronistas coloniais, como Anchieta e Cardim - o porquê de ter prevalecido a situação linguística apontada na Introdução, fechando a seção com o importante testemunho deixado por Cardim no seu Tratados da terra e gente do Brasil.

Dando sequência ao artigo, na seção intitulada A fundação das Capitanias de Ilhéus e de Porto Seguro, afirmamos que, superada tal barreira linguística, os contatos inter-étnicos puderam aprofundar-se, de modo a que fosse estabelecida uma aliança supostamente bilateral entre portugueses e tupinambás, através da qual os tupinambás forneciam parte de seus prisioneiros, capturados nas guerras inter-tribais, como escravos para os portugueses, em troca de apoio militar a ser utilizado nas referidas guerras que já travavam há séculos com os tapuias, que expulsaram para os sertões brasileiros.

Já na seção O desvelar da dominação e a "escravidão na própria terra", observamos que, com o avançar da colonização e o início da implantação dos primeiros engenhos de produção de açúcar no Sul da Bahia, o vertiginoso aumento da necessidade de cooptação de mão de obra, não mais suprida pelo sistema de aliança adotado inicialmente, teve como corolário o seu abandono, por parte dos portugueses, e o avanço militar sobre os tupinambás, com intuito de escravizá-los massivamente para o trabalho no eito dos 
engenhos açucareiros, selando, assim, o fim do que era considerada, pelos tupinambás, uma aliança militar bilateral, e fazendo aparecer a dura realidade colonial, até então não explicitada.

Por fim, na seção O Sul da Bahia e sua configuração sociolinguística no século XVI, tratamos do fato de, em sua região costeira, não termos tido a formação de pidgins e crioulos, pois, de acordo com o que expusemos ao longo do artigo, teria prevalecido a situção sociolinguística de bilinguismo, que não envolve a interrupção do uso e da transmissão geracional da língua do povo dominado, condição para a formação de pidgins e crioulos.

E, para finalizar o artigo como um todo, retomamos, nesta Conclusão, um tema colocado na Introdução, com base no historiador Bessa Freire (2004): a importância do desenvolvimento, na ciência linguística e na ciência histórica, da disciplina de história social da linguagem. Como vimos, o historiador afirma que a compreensão de dinâmicas sociolinguísticas permite a elucidação de cenários tradicionalmente abordados na ciência histórica, a exemplo das interações militares altamente violentas, que costumam ocorrer nos primeiros contatos entre povos distintos nas expansões coloniais, e de processos que contribuem para a compreensão da formação de uma nova nacionalidade.

Tendo em mente o que foi exposto até aqui, constatamos que Bessa Freire tem razão, pois foi, justamente, a fácil ultrapassagem da barreira linguística inicial que possibilitou a interação relativamente pacífica entre portugueses e tupinambás, ao permitir a negociação da aliança militar supostamente bilateral, estabelecida na primeira metade do século XVI. Portanto, compreender como se deu tal ultrapassagem de barreira linguística é crucial para compreendermos o caráter relativamente pacífico e menos chocante das relações iniciais entre esses povos, oriundos de realidades tão distintas, no referido período.

A ultrapassagem da barreira linguística inicial, ao romper a dificuldade de socialização que a ininteligibilidade linguística mútua causa, facilitou, outrossim, a implementação da prática cultural tupinambá denomiada cunhadismo ou cunhadaço, abrindo as portas para o processo de miscigenação entre portugueses e índias, dando origem a uma população cada vez maior de mamelucos. Como sabemos, com base em Ribeiro (2004 [1995]), seria justamente essa miscigenação, ocorrida nas primeiras cinco décadas de colonização, que abriria as portas para a formação do amálgama étnico que viria a - depois de introduzida a matriz africana, a partir de 1549 - compor a identidade nacional brasileira.

Por isso, o desenvolvimento da disciplina de história social da linguagem é de fundamental importância para a abertura de novos caminhos de pesquisa no âmbito da ciência histórica. Tal empreitada, inclusive, já contaria com muitos passos previamente dados, pois não são poucos os trabalhos de linguística histórica, escritos tanto no Brasil quanto em Portugal (cf. MATTOS E SILVA, 2004 e CASTRO, 2006, respectivamente), que abordam aspectos administrativos, políticos e econômicos como variáveis explicativas da formação histórica de uma língua num determinado território.

\section{REFERÊNCIAS}

ALTMAN, C. As línguas gerais sul-americanas e a empresa missionária: linguagem e representação nos séculos XVI e XVII. In: BESSA FREIRE, J. R.; ROSA, M. C. (org.). Línguas gerais: política linguística e catequese na América do Sul no período colonial. Rio de Janeiro: EDUERJ, 2003. p. 57-83.

ANCHIETA, J. de. Arte de gramática da língua mais usada na costa do Brasil. Coimbra: Oficina de Antônio de Mariz, 1595.

LUCCHESI, D., BAXTER, A. A transmissão linguística irregular. In: LUCCHESI, D., BAXTER, A., RIBEIRO, I. (org.). O português afro-brasileiro. Salvador: EDUFBA, 2009. p. 101-124.

BESSA FREIRE, J. R. Rio Babel: a história das línguas na Amazônia. Rio de Janeiro: Atlântica, 2004. 
CARDIM, F. Tratados da terra e gente do Brasil. São Paulo: Hedra, 2009 [1583]. p. 200.

CASTRO, I. Introdução à história do português. Lisboa: Colibri, 2006.

COUTO, J. A construção do Brasil. Lisboa: Cosmos, 1998.

FAUSTO, Carlos. Fragmentos de história e cultura tupinambá: da etnologia como instrumento crítico de conhecimento etnohistórico. In: CUNHA, Manuela Carneiro da (org.). História dos índios no Brasil. São Paulo: Companhia das letras, 1992. p. 381 -396.

HEMMING, J. Amazon frontier: the defeat of the Brasilian indians. Cambridge University Press, 1987.

HOLM, J. An Introduction to Pidgins and Creoles. Cambridge: Cambridge University Press, 2000.

LUCCHESI, D. A diferenciação da língua portuguesa no Brasil e o contato entre línguas. Estudos de Linguística Galega, Santiago de Compostela, v. 4, p. 45-65, 2012.

MARCÍlIO, M. L. A população do Brasil colonial. In: BETHELL, L. (org.). História da América Latina: América Latina Colonial, v. II. Trad. Mary Amazonas Leite de Barros e Magda Lopes. São Paulo: EDUSP / Brasília: Fundação Alexandre de Gusmão, 2004. p. 311-338.

MATOS, P. T. de. Population censuses in the Portuguese Empire (1750-1820): research notes. Romanian Journal of Population Studies, v. 7, n. 1, p. 1-22, 2013.

MATTOS E SILVA, R. V. Ensaios para uma sócio-história do português brasileiro. São Paulo: Parábola, 2004.

MÉTRAUX, A. The Tupinamba. In: STWEARD, Julian (org.). Handbook of south american indians. Washington: Government printing office, 1948. p. 95-139.

PARAÍSO, M. H. B. De como se obter mão de obra indígena na Bahia entre os séculos XVI e XVIII. Revista História, p. 179-208, 1993.

RIBEIRO, D. O povo brasileiro. São Paulo: Companhia das Letras, 2004 [1995].

RODRIGUES, A. Línguas brasileiras: para o conhecimento das línguas indígenas. São Paulo: Loyola, 1986.

SILVA NETO, S. da. História da língua portuguesa. Rio de Janeiro: Presença, 1957.

VILHENA, L. dos S. A Bahia no século XVIII. Salvador: Editora Itapuã, 1969 [1798-1799].

\section{()(1) $\circledast \circledast$}

Recebido em 21/09/2019. Aceito em 08/11/2019. 